\title{
A Distribution Line Protection Scheme for Network with Distributed Generation
}

\author{
Adrianti, Edwindiansyah Asharry, Muhammad Nasir \\ Universitas Andalas, Kampus Limau Manih, Padang, 25163, Indonesia
}

\section{ARTICLE INFORMATION}

Received: June 5, 2021

Revised: July 6, 2021

Available online: July 28, 2021

\section{KEYWORDS}

Distribution line protection, distributed generation, quadrilateral distance relay, directional overcurrent relay

\section{CORRESPONDENCE}

E-mail: adrianti@eng.unand.ac.id

\section{A B S T R A C T}

Installation of distributed generations (DGs) can cause performance degradation of distribution lines protection. Therefore, the objective of this paper is to propose a protection scheme that can be a solution for this protection line degradation.. The proposed scheme consist of quadrilateral distance relays at upper stream of the lines and directional overcurrent relays at downstream of the lines. The performance of the scheme was tested using Digsilent Powerfactory simulation. The simulation was carried out for four fault types, $0-50 \mathrm{Ohms}$ fault resistance and four network conditions/scenarios. The test system consist of three current source i.e. Grid, DG1 and DG2. Variation on-off state of the three current sources is applied in order to check the ability of the scheme to perform correctly for multiple network condition and possibility installation of new DG in the future. The results show that the scheme perform correctly for all bolted fault regardless of fault types, fault location and network scenarios. For three phase and two phase to ground faults the scheme perform correctly for all simulated fault resistance. However, for single line to ground faults and phase to phase faults, the scheme has limitation on maximum fault resistance that can result in correct operation. In general, the proposed scheme able to protect the distribution lines better than the scheme of previous research, but it has a slightly higher chance to perform unwanted operation.

\section{INTRODUCTION}

Distribution lines are commonly protected by overcurrent protection relays [1-4]. However, these relays may suffer degradation of their protecting performance after installation of distributed generations (DGs) on distribution networks [5-11]. The degradation occurs due to changes in DGs states (in service states or out services states) at any time, hence the magnitude and direction of normal and fault currents on a line will vary significantly. The variation of magnitude and direction of electrical current on the lines cause difficulties in finding correct settings for the overcurrent relays[5].

In order to overcome the protection problems, several publication propose adaptive overcurrent protection as a distribution line protection with DG installed [5, 6, 12-14]. These protections are considered effective, however they are usually need more sophisticated equipment and communication system. Therefore, the cost of the protections will be high and it will not cost effective for small DGs.

Other papers propose implementation of distance relays for distribution lines with DGs [15-19]. Distance relays are usually used for transmission lines protection. Distance relays work based on detected impedance hence their setting will not affected by changes of current sources on the network. Therefore, it is predicted that distance relays will work correctly on the distribution lines, even though the current sources (DGs) continuously change on the network

Previous study in [15], discover that mho distance relays works well with changing in current sources. Three system conditions are simulated i.e. DG and grid work, DG off and grid works, also DG works and grid off (islanding operation). The distance relays operate correctly for the three system conditions. However, when fault resistances are introduced on the faults, distance relays that see fault currents from the DG, are experience incorrect operation.

In order to increase distance relays capability in detecting resistive faults, quadrilateral distance relays were used in the following research [16]. The research is successfully in increasing distance relay capability for the detecting resistive faults but only for distance relays that see fault current from grid. On the other hand, the distance relays, that see fault current from the DG has less resistive fault covered due to the smaller of the DG fault current if compared to grid fault current. This less current results in larger impedance seen by the relays than it should be.

In this research, the poor performance of quadrilateral distance relays are trying to be fixed by applying directional overcurrent relay on distribution lines that sees fault currents from DG (downstream of the lines). Overcurrent relays tend unaffected by resistance of faults. Therefore, it will be a good candidate for protecting DG side (downstream side) of distribution lines. While 
grid side (upper stream side) of the distribution lines are protected by quadrilateral distance relays. This scheme is proposed as protection of distribution lines with distributed generation present on the network

The aim of this paper is to introduce and assess a proposed protection schemes that consist of quadrilateral distance relays and directional overcurrent relays, in protecting distribution lines. The scheme is expected to be able to work correctly irrespective of changing in network current sources.

\section{THE PROPOSED PROTECTION SCHEME}

The distribution line protection scheme is designed with an objective that the scheme will continue to work correctly regardless any changes in generation or current sources on the distribution network. The changes are including connection of new DGs, disconnection of any DG and disconnection of grid. Type of DG that is considered in this research is synchronous machine DG, because it produces significant large current during short circuit faults on the network, hence the faulted section needs to be disconnected quickly using a protection system.

In previous research [16], it has been proposed a quadrilateral distance protection scheme for distribution line protection. The scheme works correctly for any bolted short circuit faults. However, when resistive single line to ground or two phase faults are applied to the lines, the relays that detect fault current from DG (downstream part of lines), fail to detect the faults. The condition exist due to the relatively less fault current from DG. Since DGs are small capacity of power generation plants, they produce less fault current than non DG power plants.

In this research, the quadrilateral distance relays on downstream of the lines are changed with directional overcurrent protection. Overcurrent relays can be set at low value i.e. slightly higher than maximum load current, hence they still able to detect resistive one phase or two phase faults. Overcurrent relays need directional element in order to discriminate particular fault locations. The schematic of the proposed protection scheme is shown in figure 1 .

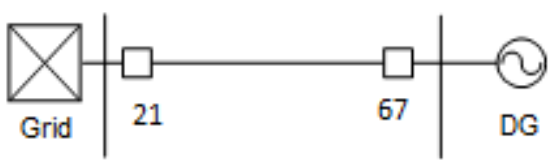

Figure 1. The proposed distribution line protection scheme

From figure 1, the upper stream part of the line is protected by a quadrilateral distance relay (ANSI number: 21) and downstream part is protected by a directional overcurrent relay (DOCR) (ANSI number: 67). Since overcurrent relay settings need to be evaluated or changed with change of fault current sources, hence this protection scheme is suitable if downstream of the directional overcurrent relay will not be installed with additional DG in the future. However, the scheme is expected to work correctly if additional DGs are installed on upper stream of quadrilateral distance relay, since distance relays able to work with changing of current sources.
The setting of quadrilateral distance relays consist of impedance settings and resistance settings. Impedance setting is based on positive sequence of line impedance and calculated using equation (1) to (3) for zone 1 to zone 3 [20].

$$
\begin{aligned}
& Z_{\text {zone } 1}=0.8 * Z_{\text {line } 1} \\
& Z_{\text {zone } 2}=Z_{\text {line } 1}+0.5 * Z_{\text {line } 2} \\
& Z_{\text {zone } 3}=Z_{\text {line } 1}+1.2 * Z_{\text {line } 2}
\end{aligned}
$$

where $Z_{\text {line } 1}$ is impedance of the line 1 i.e. the line where the relay (R1) is located as shown in figure $2 . Z_{\text {line } 2}$ is impedance of line 2 i.e. the line next to line 1 (see figure 2 ).

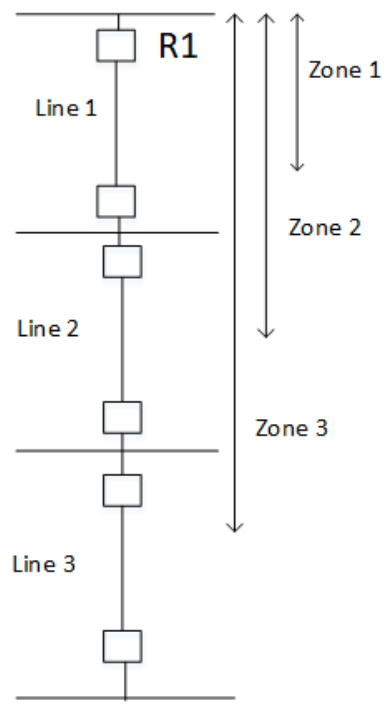

Figure 2. Zones of a distance relay

The resistance settings are based on maximum load impedance that calculated using (4) [20].

$$
Z_{\text {load }}=\frac{K V_{\text {nom }} 1000}{\sqrt{3} I_{C T}}
$$

Where, $K V_{\text {nom }}$ is nominal voltage $(\mathrm{kV})$ of the distribution lines and $I_{C T}$ is nominal primary current of CT of the distance relay. Resistance setting consists of phase fault and ground fault. Phase fault resistance setting is 0.6 times of $Z_{\text {load }}$ and ground fault resistance setting is 0.8 limes of $Z_{\text {load }}$ [20].

The directional overcurrent relays has standard invers characteristics. They settings consist of current settings, time settings and directional settings. Current settings are based on maximum load current that seen by the relays and calculated with (5).

$I_{\text {set }}=(1.1$ to 1.4$) I_{\text {load }}$

Where, $I_{\text {load }}$ is maximum normal load current seen by the relay. Time setting is informed of Time Multiplier Setting (TMS). The TMS of standard invers characteristic is calculated using (6).

$$
t_{o p}=\frac{0.14 T M S}{\left(\frac{I_{f}}{\text { Iset }}\right)^{0.02}-1}
$$


where $t_{o p}$ is operating time of the relay (in seconds) that should be coordinated with other overcurrent relays. $I_{f}$ is maximum fault current that seen by the relay. Directional setting is chosen from downstream to upper stream of the protected distribution line, hence the relay only observes current that comes from the downstream DG.

\section{TESTING METHODOLOGY}

The proposed scheme is assessed using simulation method with Digsilent Powerfactory. The test system is a $20 \mathrm{kV}$ distribution network that show in figure 3 and 4 . DG 1 is installed on bus 4 through a 2.5 MVA step up transformer. Line 1 and line 2 are protected with the proposed scheme. R1 and R2 are quadrilateral distance relays, while DOCR1 and DOCR 2 are directional overcurrent relays with standard invers characteristics. The test system data are presented in Table 1 and 2 . The $150 \mathrm{kV}$ substation (grid) has 619 short circuit MVA.

Table 1. Line impedance of test system

\begin{tabular}{clll}
\hline Line & $\mathrm{Z}_{1}(\mathrm{Ohm})$ & $\mathrm{Z}_{0}(\mathrm{Ohm})$ & Length $(\mathrm{km})$ \\
\hline 1 & $2.22+\mathrm{j} 3.394$ & $3.73+\mathrm{j} 1.66$ & 10.27 \\
2 & $5.297+\mathrm{j} 8.097$ & $8.896+\mathrm{j} 3.964$ & 24.5 \\
\hline
\end{tabular}

Table 2. DG capacities and loads

\begin{tabular}{lcc}
\hline \multicolumn{1}{c}{ Component } & Capacity (KW) & Power factor \\
\hline Load bus 4 & 382 & 0.85 \\
Load bus 3 & 1700 & 0.86 \\
Load bus 2 & 500 & 0.90 \\
DG1 & 2000 & 0.95 \\
DG2 & 2000 & 0.95 \\
\hline
\end{tabular}

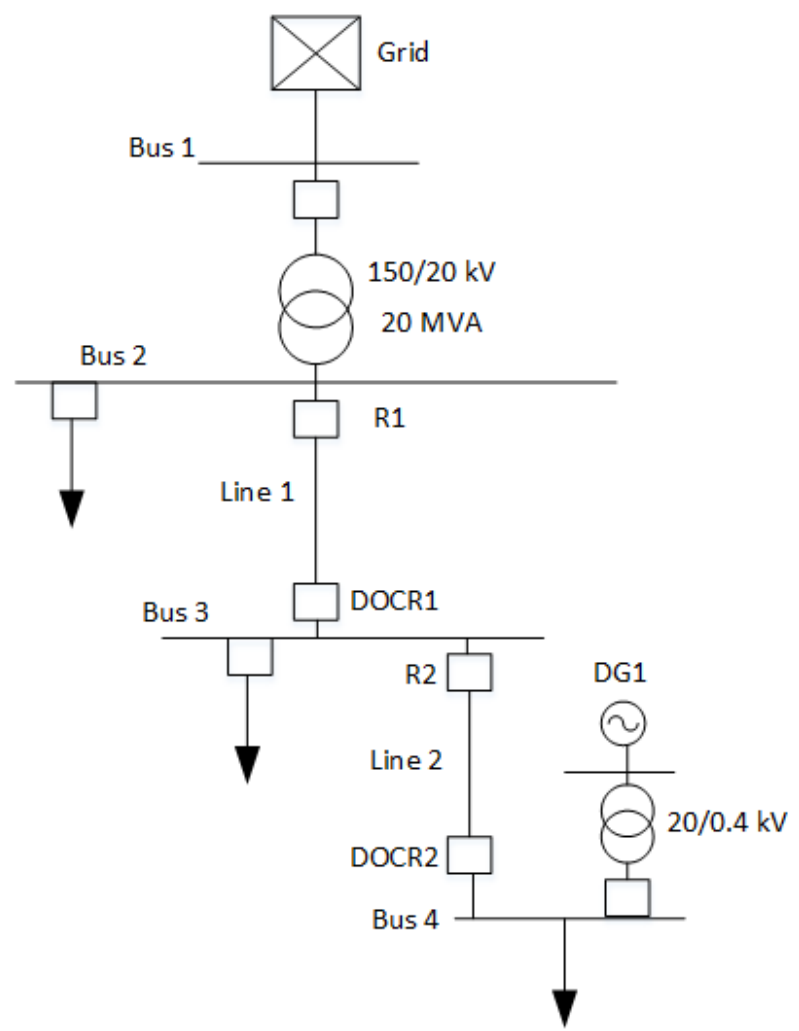

Figure 3. Single line diagram of existing test system
Setting of relay R1, R2, DOCR1 and DOCR2 are calculated based on network condition in Figure 3. The settings are then tested with bolted faults on line 1, line 2, bus 2, bus 3 and bus 4 . Bolted faults are faults with zero fault resistance. The tested faults are including single phase to ground, two phase, two phase to ground and three phase fault. If any of the relays do not perform correctly, then the relay settings will be revised and tested again. The relays are also examined with resistive faults from $1 \mathrm{Ohm}$ to $50 \mathrm{Ohm}$ resistance.

In order to assess capability of the scheme to work correctly with change of current sources, four network scenarios are applied as shown in Table 3. Scenario 1 is the existing network as shown in figure 3. Scenario 2, 3, and 4 are future network conditions with additional DG (DG 2) at bus 2 (Figure 4).

Table 3. Network Scenario

\begin{tabular}{ccccc}
\hline Scenario & Grid & DG1 & DG2 & info \\
\hline 1 & On & On & NA & Existing condition \\
2 & On & On & On & Future condition \\
3 & Off & On & On & Future condition \\
4 & On & Off & On & Future condition \\
\hline
\end{tabular}

$\mathrm{NA}=$ not available

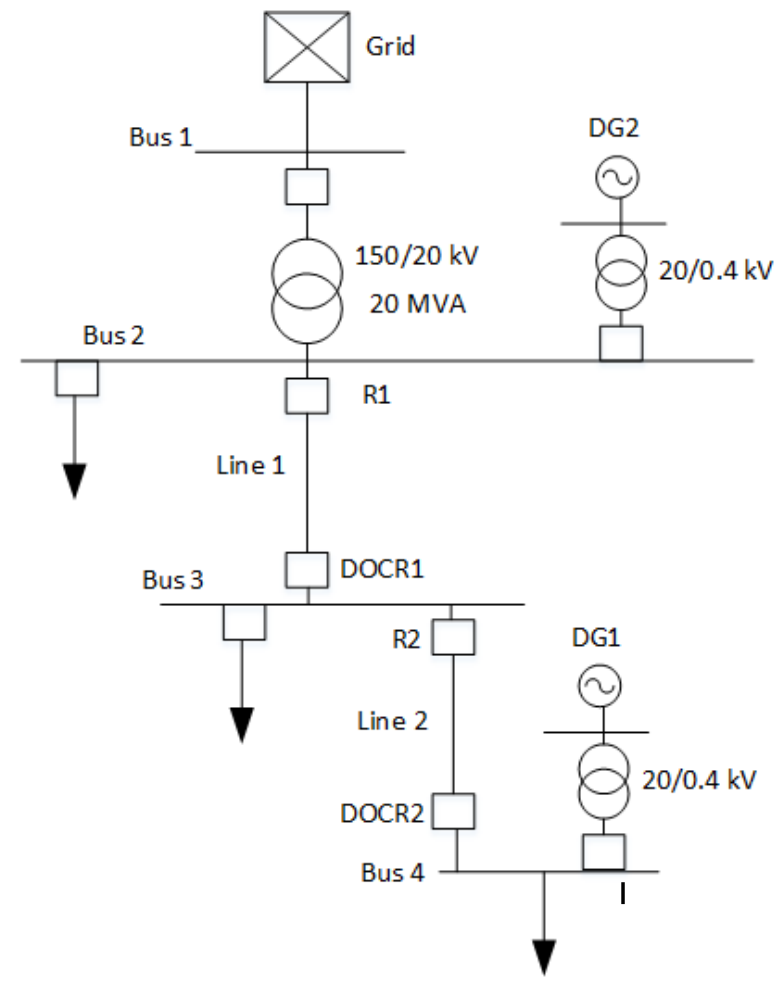

Figure 4. Single line diagram of future condition

In each scenario, the relays are tested with four types of fault and the same variation of fault resistances. In order to examine zone 1 and zone 2 operation of the distance relays, the simulate faults are located at: $60 \%$ of line 1 (measured from bus 2) and $40 \%$ of line 2 (measured from bus 3). 


\section{RESULTS AND DISCUSSION}

The setting of quadrilateral distance relays are shown in Table 4 while setting of DOCRs are shown in Table 5. At Table 4, it can be seen that the setting of quadrilateral distance relays consist of impedance settings (Z), resistance settings for phase faults (Rp) and resistance settings for earth faults (Re). The DOCRs have 3 settings parameter, i.e. pick up current (Iset), time setting multiplier (TMS) and maximum torque angle (MTA). Each relay have Voltage Transformer with ratio 20000:110 Volt and Current Transformer with ratio 100:1 Ampere.

Table 4. Settings of Quadrilateral Distance Relays

\begin{tabular}{clcc}
\hline \multirow{2}{*}{ Zone } & \multirow{2}{*}{ Setting type } & \multicolumn{2}{c}{ Setting (primary, Ohm) } \\
\cline { 3 - 4 } & & R1 & R2 \\
\hline \multirow{2}{*}{1} & $\mathrm{Z}$ & 3.25 & 7.74 \\
& $\mathrm{Rp}$ & 69.28 & 69.28 \\
& $\mathrm{Re}$ & 92.37 & 92.37 \\
\hline \multirow{2}{*}{2} & $\mathrm{Z}$ & 8.89 & 9.68 \\
& $\mathrm{Rp}$ & 69.28 & 69.28 \\
& $\mathrm{Re}$ & 92.37 & 92.37 \\
\hline \multirow{2}{*}{3} & $\mathrm{Z}$ & 13.73 & $\mathrm{NA}$ \\
& $\mathrm{Rp}$ & 69.28 & $\mathrm{NA}$ \\
& $\mathrm{Re}$ & 92.37 & $\mathrm{NA}$
\end{tabular}

Relay angle $56^{\circ}$

Table 5. Settings of Directional Overcurrent Relays

\begin{tabular}{cccc}
\hline Relay & I set (primary, A) & TMS & MTA \\
\hline DOCR1 & 21.6 & 0.05 & $30^{\circ}$ \\
DOCR2 & 86.9 & 0.12 & $30^{\circ}$ \\
\hline
\end{tabular}

The scheme was tested using Digsilent Powerfactory fault simulation. The test results show capability of the scheme in protecting the distribution lines. For bolted faults, all relays in the scheme perform correctly in all scenarios as shown in Table 6 . The relays perform correctly means that the relays trip when they should trip and they do not trip when they should not.

An example of bolted LG fault simulation results is shown in Figure 5 to Figure 7. The fault occurs on $40 \%$ length of line 2 (measured from bus 3). The R1 detect the fault on zone 2 as shown by R-X diagram in figure 5 and $\mathrm{R} 2$ detect the fault on zone 1 as shown by $\mathrm{R}-\mathrm{X}$ diagram in Figure 6. The DOCR1 will not detect the fault as the fault current direction is opposite from the setting (figure 7). DOCR2 detect the fault and trip in 0.09 second (figure 8).

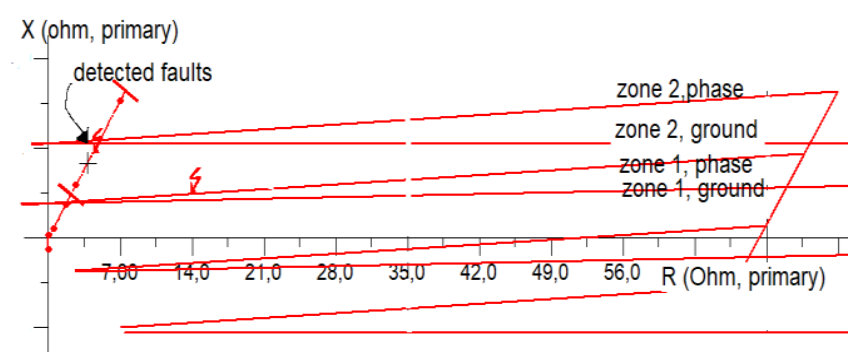

Figure 5. R-X diagram of R1 for LG fault on line 2
Table 6. Simulation result for bolted faults

\begin{tabular}{|c|c|c|c|c|}
\hline \multirow{2}{*}{ Fault type } & \multicolumn{4}{|c|}{ Detection of } \\
\hline & $\mathrm{R} 1$ & $\mathrm{R} 2$ & DOCR 1 & DOCR2 \\
\hline \multicolumn{5}{|c|}{ Fault location on line 1 at $60 \%$ of line length from bus 2} \\
\hline LG & 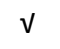 & $\checkmark$ & 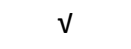 & $v$ \\
\hline LL & $\sqrt{ }$ & $\checkmark$ & $\checkmark$ & $\checkmark$ \\
\hline LLG & $\sqrt{ }$ & $\checkmark$ & $\sqrt{ }$ & 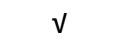 \\
\hline LLL & $\sqrt{ }$ & $\sqrt{ }$ & 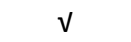 & $\sqrt{ }$ \\
\hline
\end{tabular}

Fault location on line 2 at $40 \%$ of line length from bus 3

\begin{tabular}{ccccc} 
LG & $v$ & $v$ & $v$ & $v$ \\
LL & $v$ & $v$ & $v$ & $v$ \\
LLG & $v$ & $v$ & $v$ & $v$ \\
LLL & $v$ & $v$ & $v$ & $v$ \\
\hline
\end{tabular}

Fault location on bus 2 or bus 3 or bus 4

$\begin{array}{ccccc}\text { LG } & v & v & v & v \\ \text { LL } & v & v & v & v \\ \text { LLG } & v & v & v & v \\ \text { LLL } & v & v & v & v\end{array}$

$\bar{V}=$ perform correctly (trip when it should trip or do not trip when it should not trip)

$\mathrm{x}=$ perform incorrectly (do not trip when it should trip or trip when it should not)

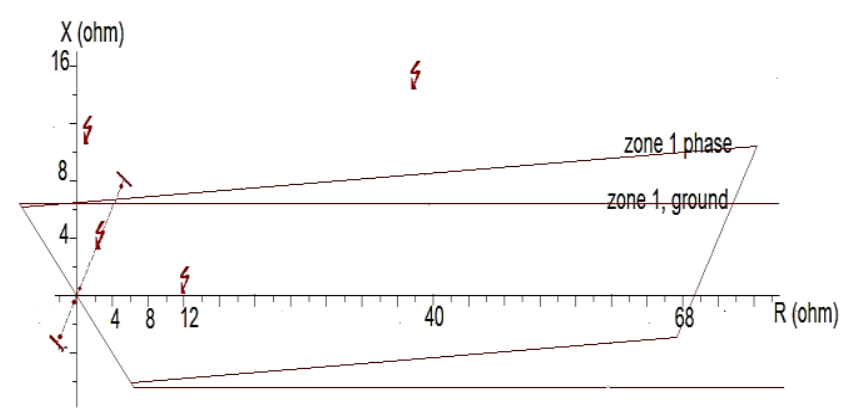

Figure 6. R-X diagram of R2 for LG fault on line 2

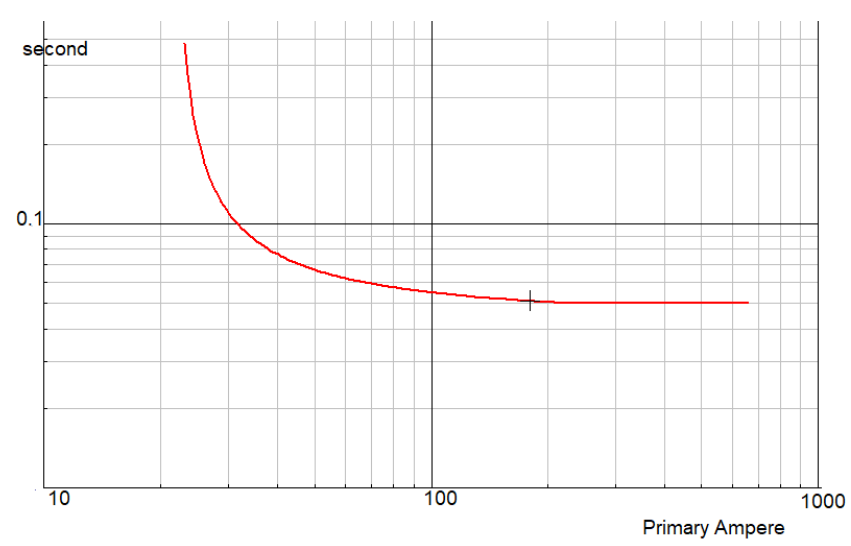

Figure 7. Time over current plot of DOCR1 for LG fault on line 2 


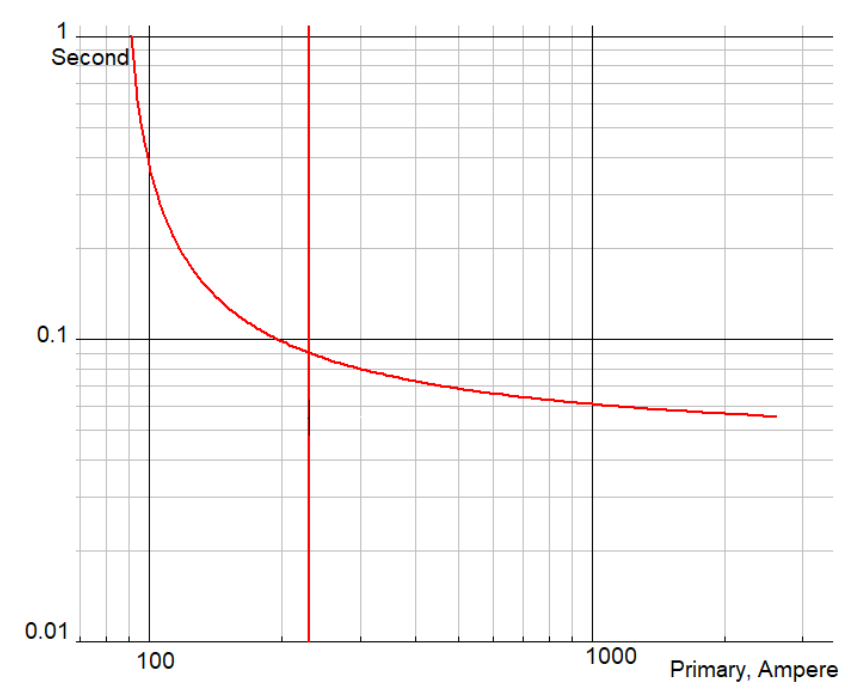

Figure 8. Time over current plot of DOCR 2 for LG fault on line 2

For resistive faults, some relays may perform incorrectly depend on types of fault and magnitude of fault resistances. Both distance relay (R1 and R2) work correctly for LLL and LLG faults on the line 1 and line 2, for all simulated fault resistance quantities. However for LG and LL faults, the distance relays work correctly with maximum fault resistance around $10 \mathrm{Ohm}$ (more or less depending fault type and location). This result confirm the previous research in [16].

Both directional overcurrent relays (DOCR1 and DOCR2) perform correctly in all network scenarios for LLL and LLG faults for all simulated fault resistance quantities. For LG and LL fault simulation, the performances of DOCR 1 and DOCR 2 are shown in Table 7 and Table 8. In Table 7 and 8, simulation results for scenario 4 are not shown, because in scenario 4 , there is no fault current flown from DG1, hence DOCR1 and DOCR2 will not work as they do not see any faults. Therefore the both relays always perform well in scenario 4 .

Table 7. DOCR simulation result for faults on $60 \%$ line 1

\begin{tabular}{cccccc}
\hline \multirow{4}{*}{ Type } & Rf & \multicolumn{2}{c}{ Scenario 1\&2 } & \multicolumn{2}{c}{ Scenario 3 } \\
\cline { 3 - 6 } & $(\Omega)$ & DOCR 1 & DOCR2 & DOCR 1 & DOCR2 \\
\hline \multirow{4}{*}{ LG } & 1 & v & v & v & v \\
& 4 & v & v & v & v \\
& 10 & v & x & v & v \\
& 20 & v & x & v & v \\
& 30 & x & x & v & v \\
& 40 & x & x & v & v \\
& 50 & x & x & v & x \\
\hline \multirow{4}{*}{ LL } & 1 & v & v & v & v \\
& 10 & v & v & v & v \\
& 20 & v & x & v & v \\
& 30 & v & x & v & v \\
& 40 & v & x & v & v \\
& 50 & v & x & v & v \\
\hline
\end{tabular}

$\mathrm{v}=$ perform correctly (trip when it should trip or do not trip when it should not trip), $\mathrm{x}=$ perform incorrectly (do not trip when it should trip or trip when it should not)

Table 8. DOCR simulation result for faults on $40 \%$ line 2

\begin{tabular}{|c|c|c|c|c|c|}
\hline \multirow{2}{*}{ Type } & \multirow{2}{*}{$\operatorname{Rf}(\Omega)$} & \multicolumn{2}{|c|}{ Scenario $1 \& 2$} & \multicolumn{2}{|c|}{ Scenario 3} \\
\hline & & DOCR 1 & DOCR2 & DOCR 1 & DOCR2 \\
\hline \multirow{7}{*}{ LG } & 1 & $\mathrm{v}$ & $\mathrm{v}$ & $\mathrm{v}$ & $\mathrm{v}$ \\
\hline & 10 & $\mathrm{x}$ & $\mathrm{v}$ & $\mathrm{x}$ & $\mathrm{v}$ \\
\hline & 13 & $\mathrm{x}$ & $\mathrm{v}$ & $\mathrm{x}$ & $\mathrm{v}$ \\
\hline & 20 & $\mathrm{x}$ & $\mathrm{x}$ & $\mathrm{x}$ & $\mathrm{v}$ \\
\hline & 30 & $\mathrm{x}$ & $\mathrm{x}$ & $\mathrm{v}$ & $\mathrm{v}$ \\
\hline & 40 & $\mathrm{x}$ & $\mathrm{x}$ & $\mathrm{v}$ & $\mathrm{v}$ \\
\hline & 50 & $\mathrm{x}$ & $\mathrm{x}$ & $\mathrm{v}$ & $\mathrm{v}$ \\
\hline \multirow{6}{*}{ LL } & 1 & $\mathrm{v}$ & $\mathrm{v}$ & $\mathrm{v}$ & $\mathrm{v}$ \\
\hline & 10 & $\mathrm{v}$ & $\mathrm{v}$ & $\mathrm{v}$ & $\mathrm{v}$ \\
\hline & 20 & $\mathrm{x}$ & $\mathrm{v}$ & $\mathrm{v}$ & $\mathrm{v}$ \\
\hline & 30 & $\mathrm{x}$ & $\mathrm{x}$ & $\mathrm{v}$ & $\mathrm{v}$ \\
\hline & 40 & $\mathrm{x}$ & $\mathrm{x}$ & $\mathrm{v}$ & $\mathrm{v}$ \\
\hline & 50 & $\mathrm{x}$ & $\mathrm{x}$ & $\mathrm{x}$ & $\mathrm{v}$ \\
\hline
\end{tabular}

$\mathrm{v}=$ perform correctly (trip when it should trip or do not trip when it should not trip),

$\mathrm{x}=$ perform incorrectly (do not trip when it should trip or trip when it should not)

DOCR 1 is primary protection for faults on line 1 and it is found that this relay perform well for LL fault for all simulated fault resistance (Table 7). The worst failure to operate of DOCR1 is for LG fault in scenario 1 and scenario 2 where it perform incorrectly during fault resistance start from $30 \mathrm{Ohm}$.

For fault on line 2, DOCR 1 should not operate as the faults occur behind the relay. However, from the simulation it is found in several simulation this relay perform mal-operation. The worst maloperation of DOCR is for scenario 3 during $10 \mathrm{ohm}$ resistance LG fault. Fault resistance has effect in shifting current phase angle, hence the faults will be detected at incorrect operating torque zone.

DOCR 2 is primary protection for faults on line 2 . From results in Table 8, DOCR 2 operates correctly in all simulation of scenario 3, while for scenario 1 and 2, DOCR 2 starts to fail for fault resistance $20 \mathrm{Ohm}$ and $30 \mathrm{Ohm}$. DOCR 2 fail to operate for fault resistance higher than 20 or $30 \mathrm{Ohm}$, because the high fault resistance reduce the fault current becoming less than the relay setting.

For faults on line 1, DOCR 2 acts as back up protection of DOCR 1. Table 7 shows that DOCR 2 starts to fail to operate at 10 and 20 Ohm fault resistance for scenario 1 and 2 respectively, while for scenario 3, it is at $50 \mathrm{Ohm}$. These results show that for faults on line 1, fault resistances that cause fault current less DOCR 2's setting are smaller than for faults on line 2. This condition can be explained as follows. DOCR 2 detects fault currents that supplied from DG 1. From DG 1, Line 1 is farther than line 2, hence faults on line 1 generate smaller fault current from DG1 than faults on line 2. Therefore, smaller fault resistance of faults on line 1 will generate current below DOCR 2 setting. 
The main question that needs to be answer is : Does this proposed scheme perform better than previous scheme i.e. all quadrilateral distance relays in [16]? In order to answer this question, the previous scheme is also simulated using the same distribution network. The results are shown in Table 9. Quad 2' is a quadrilateral distance relay that installed at DOCR2 position, while Quad 1' is a quadrilateral distance relay that installed at DOCR1 position.

Table 9. Maximum fault resistance (Ohm) for correct operation of DOCR and its equivalent Quadrilateral Distance Relay

\begin{tabular}{ccccccc}
\hline \multirow{2}{*}{ Relay } & \multicolumn{2}{c}{ Scenario 1 } & \multicolumn{2}{c}{ Scenario 2 } & \multicolumn{2}{c}{ Scenario 3 } \\
\cline { 2 - 7 } & LG & LL & LG & LL & LG & LL \\
\hline Fault at line $1,60 \%$ length from bus 2 & & & \\
\hline DOCR2 & 4 & 10 & 4 & 10 & 50 & 50 \\
Quad 2 & 0 & 1 & 0 & 0 & 1 & 1 \\
\hline DOCR1 & 20 & 50 & 20 & 50 & 50 & 50 \\
Quad 1 & 0 & 0 & 0 & 0 & 1 & 30 \\
\hline Fault at line $2,40 \%$ length from bus 3 & 13 & 20 & 50 & 50 \\
\hline DOCR2 & 13 & 20 & 13 & 10 & 1 & 50 \\
\hline Quad 2 & 1 & 10 & 1 & 10 & 1 & 40 \\
\hline DOCR1 & 1 & 10 & 1 & 50 & 50 & 50 \\
\hline Quad 1' & 50 & 50 & 50 & & &
\end{tabular}

From Table 9 can be seen that DOCR1 and DOCR2 perform correctly at higher resistance of resistive faults than the quadrilateral distance relays for faults at line 1 . For fault at line 2, DOCR 2 also have higher fault resistance covered than the quad 2'. However, DOCR1 experience unwanted operation for LG and LL faults on line 2 at relatively lower fault resistance than Quad 1'. Therefore for these condition, the quadrilateral distance relay perform better.

\section{CONCLUSIONS}

The proposed protection scheme perform correctly in the four scenarios for all bolted faults, also for LLL and LLG resistive faults. For LG and LL resistive faults, both distance relays performs correctly for maximum around $10 \mathrm{Ohm}$ fault resistance. While for DOCRs, the maximum fault resistance that can result in the relays correct performance varies from $1 \mathrm{Ohm}$ to $50 \mathrm{Ohm}$ depending fault types, fault location and network scenario. The DOCRs of the proposed scheme able to work correctly at higher fault resistance than their equivalent quadrilateral distance relays from previous research. However, quadrilateral distance relays perform better in detecting the direction of fault currents than DOCRs. How to improve the DOCR shortcoming will be a problem that need to be solve in the future research.

\section{REFERENCES}

[1] R. Bansal, Power system protection in smart grid environment: CRC Press, 2019.

[2] J. C. Das, Power System Protective Relaying: CRC Press, 2017.

[3] O. S. E. Atwa, Practical Power System and Protective Relays Commissioning: Elsevier Science, 2019.
[4] Y. G. Paithankar and S. R. Bhide, Fundamentals of power system protection. New Delhi: PHI Learning Private Limited, 2010.

[5] P. Mahat, Z. Chen, B. Bak-Jensen, and C. L. Bak, "A Simple Adaptive Overcurrent Protection of Distribution Systems With Distributed Generation," IEEE Transactions on Smart Grid, vol. 2, pp. 428-437, Sept. 2011.

[6] F. Coffele, C. Booth, and A. Dyśko, "An Adaptive Overcurrent Protection Scheme for Distribution Networks," IEEE Transactions on Power Delivery, vol. 30, pp. 561-568, 2015.

[7] F. Coffele, C. Booth, and G. Burt, "Detailed Analysis of The Impact of Distributed Generation and Active Network Management on Network Protection System," in CIRED 21st International Conference on Electricity Distribution, Frankfurt, 2011.

[8] M. H. Bollen and F. Hassan, Integration of distributed generation in the power system vol. 80: John Wiley \& Sons, 2011.

[9] P. T. Manditereza and R. Bansal, "Renewable distributed generation: The hidden challenges - A review from the protection perspective," Renewable and Sustainable Energy Reviews, vol. 58, pp. 1457-1465, 2016.

[10] M. Norshahrani, H. Mokhlis, A. H. Abu Bakar, J. J. Jamian, and S. Sukumar, "Progress on Protection Strategies to Mitigate the Impact of Renewable Distributed Generation on Distribution Systems," Energies, vol. 10, p. 1864, 2017.

[11] D. R. Bhise, R. S. Kankale, and S. Jadhao, "Impact of distributed generation on protection of power system," in 2017 International Conference on Innovative Mechanisms for Industry Applications (ICIMIA), 2017, pp. 399-405.

[12] S. M. Brahma and A. A. Girgis, "Development of Adaptive Protection Scheme for Distribution Systems with High Penetration of Distributed Generation," IEEE Transaction on Power Delivery, vol. 19, pp. 56-63, 2004.

[13] J. Ma, C. Mi, T. Wang, J. Wu, and Z. Wang, "An Adaptive Protection Scheme for Distributed Systems with Distributed Generation," presented at the IEEE Power and Energy Society General Meeting, San Diego, 2011.

[14] J. Ma, J. Liu, Z. Deng, S. Wu, and J. S. Thorp, "An adaptive directional current protection scheme for distribution network with DG integration based on fault steady-state component," International Journal of Electrical Power \& Energy Systems, vol. 102, pp. 223-234, 2018/11/01/ 2018.

[15] A. Adrianti, A. R. Sijabat, and M. Nasir, "Analyzing Performance of Distance Relay in Protecting Distribution Lines with Distributed Generation," in 3rd International Conference on Electrical Engineering and Computer Science (ICECOS), Batam, Indonesia, 2019.

[16] A. Adrianti, M. Nasir, and M. Rivaldi, "Studi Pemanfaatan Relai Jarak Quadrilateral untuk Proteksi Saluran Distribusi dengan Pembangkit Tersebar," Jurnal Rekayasa Elektrika, vol. $16,2020$.

[17] V. C. Nikolaidis, C. Arsenopoulos, A. S. Safigianni, and C. D. Vournas, "A distance based protection scheme for distribution systems with distributed generators," in 2016 Power Systems Computation Conference (PSCC), 2016, pp. 1-7.

[18] K. Pandakov, H. K. Høidalen, and J. I. Marvik. (2016, Implementation of Distance Relaying in Distribution Network with Distributed Generation. IET Conference Proceedings, $7 \quad .7$. Available: https://digitallibrary.theiet.org/content/conferences/10.1049/cp.2016.0021

[19] A. Sinclair, D. Finney, D. Martin, and P. Sharma, "Distance Protection in Distribution Systems: How It Assists With Integrating Distributed Resources," IEEE Transactions on Industry Applications, vol. 50, pp. 2186-2196, 2014.

[20] Alstom-Grid. (2011, 25/06/2014). Network Protection \& Automation Guide. Available: 
http://www.alstom.com/grid/products-and-services/Substationautomation-system/protection-relays/Network-ProtectionAutomation-Guide-NEW-2011-Edition/

\section{NOMENCLATURE}

LG Single phase to ground fault

LL Phase to phase fault

LLG Two phase to ground fault

LLL Three phase fault

DOCR Directional overcurrent relay

TMS Time multiplier setting

\section{AUTHOR(S) BIOGRAPHY}

\section{Adrianti}

Adrianti currently is a Senior Lecture at Electrical Engineering Department of Universitas Andalas, Padang, Indonesia. She finished PhD study at University of Strathclyde, Glasgow, United Kingdom in 2015. Her research interest is including power system protection, power system reliability and distributed generation.

\section{Edwindiansyah Asharry}

Edwindiansyah Asharry currently is a master degree student at Electrical Engineering Department of Universitas Andalas, Padang,Indonesia. His research interest is including power system protection.

\section{Muhammad Nasir}

Muhammad Nasir received the Ph.D. degree in electrical engineering from the Faculty of Engineering, University of Strathclyde, Glasgow, UK. He has been with the Electrical Engineering Department, Faculty of Engineering, Universitas Andalas, since 1998, where is currently a senior lecturer. His current research interests include power system protection, optical sensor modelling and application for protection system, and distributed generation. 